\title{
SUITABILITY OF SOME BOTANICAL PESTICIDES (NEEM, GARLIC AND RED CHILI) AGAINST DRY FISH INSECTS (Dermestes sp. LARVAE AND Necrobia sp. ADULT)
}

\author{
A. A. K. M. Nowsad, R. Mondal, M. N. Hassan, M. M. Hossain \\ and M. R. Islam \\ Department of Fisheries Technology, Bangladesh Agricultural University \\ Mymensingh-2202, Bangladesh
}

\begin{abstract}
Acetone extracts of red chili (Capsicum frutescens), garlic (Allium sativum) and neem (Azadirachta indica) were used to evaluate their insecticidal effects against a dry fish beetle, Dermestes sp. larvae and a mite, Necrobia sp. adult. The concentration of plant extracts were 60,80 and $100 \%$ for Dermestes sp. larvae and 10, 15 and $20 \%$ for Necrobia sp. adult. The mortality of Necrobia sp. at 24, 48 and 72 hours after treatment (HAT) indicated that red chili extract possessed the highest insecticidal effect followed by neem and garlic. Mortality was found to be directly proportional to the concentration of plant extracts. For Necrobia $\mathrm{sp}$. (adult) $\mathrm{LC}_{50}$ values of red chili, neem and garlic were $0.78,0.85$ and $1.68 \%$, respectively at 24 HAT. Red chili was found to possess the highest insecticidal effect among these three with the highest toxic effect at 48 HAT $(0.29 \%)$ and 72 HAT $(0.03 \%)$. For the larvae of Dermestes $s p$., the $\mathrm{LC}_{50}$ values of red chili was $0.60 \%$, neem $0.69 \%$ and garlic $1.15 \%$ at $24 \mathrm{HAT}$, again indicating that red chili had the highest insecticidal effect on dry fish insects.
\end{abstract}

Key Words: Neem, garlic, red chili, toxic effects, dry fish

\section{INTRODUCTION}

In Bangladesh, during storage dry fishes are attacked by several species of dermestid beetle, viz., Dermestes maculatus, D. frischii, D. ater and mite, Necrobia rufipes (FAO, 1981; Nowsad, 1995). Fish that are cured and has low moisture content provides a food for beetles, particularly the larvae and to a lesser extent, the adults of Dermestes sp. and Necrobia sp. The damaged caused by insect infestation is an important cause of economic and physical loss of dry fish in tropical countries (Poulter et al. 1988). Losses of cured fish can be as much as $40 \%$ during storage and losses of up to $30 \%$ have been caused by beetle and mite infestation (FAO, 1981; Meynell, 1978).

Control of pest by the routine use of chemical insecticides are practiced in many countries in dry fish but it creates several problems in agro-ecosystem such as direct toxicity to beneficial insects, fishes and man, pesticides resistance, health hazard and increased environmental and social costs (Pimental et al., 1980). Sometimes persistent pesticides 
accumulate in the higher food chain of both wild life and human and become concentrated by bio-magnification (Metcalf and Luckmann, 1975).

Botanical insecticides are considered to be the alternative to synthetic chemical pesticides since these compounds are biodegradable and less persistent in the environment (Golob and Webley, 1980; Talukder and Howse, 1993, 1995). Plants are the rich source of insecticidal compounds and the effectiveness of these compounds has been demonstrated against many stored product insects (Xie et al., 1995). Extracts of the neem (Azadirachta indica), red chili (Capsicum frutescens) and garlic (Allium sativum) have yielded botanical insecticides which have been tested extensively in agricultural situations (Sighamony, 1986). Since these products have been shown to be effective against many pests, including beetle and almost exclusively phytophagous, they might also be a safe alternative to synthetic chemicals for the control of storage beetle and mites of dry fish, such as Dermestes $s p$. and Necrobia $s p$. Considering this, the suitability of neem, garlic and red chili in terms of insecticidal and repellent effects against common dry fish beetle and mite was tested.

\section{MATERIALS AND METHODS}

\section{Collection and rearing of insect}

The test insects, Necrobia sp. adult and Dermestes sp. larvae were collected from the dry fish markets of Mymensingh town and were maintained in the Postgraduate Laboratory of the Department of Fisheries Technology, BAU. The insects were reared on crushed dry fish in plastic jars.

\section{Collection and processing of plant materials}

Neem leaves were collected from the surroundings of BAU campus, Mymensingh. After bringing them to the laboratory, they were washed in running water, kept in the shade for air drying and then dried in the oven at $60^{\circ} \mathrm{C}$ to gain constant weight. Garlic and red chili were purchased from the local market. Both garlic and red chili were dried in oven at $50^{\circ} \mathrm{C}$ for $2-3$ hours to remove moisture.

\section{Preparation of plant dust and extracts}

Plant dusts were prepared by pulverizing the dried plant materials with the help of a grinder. The dusts were passed through a 25-mesh sieve to obtain a fine and uniform dust. The dusts were preserved in airtight Zip-lock ${ }^{\circledR}$ polythene bags till their use in extract preparation.

Ten gram of each of the dusts were taken in a $500 \mathrm{ml}$ beaker and separately mixed with $100 \mathrm{ml}$ acetone. Then the mixture was stirred for 30 minutes by a magnetic stirrer (at 3000 rpm) and left for 24 hours. The mixture was filtered through a fine cloth and again through the filter paper (Whatman No. 1). The filtered materials were taken into a round bottom flask and condensed by evaporation of the solvent in a water bath at $45^{\circ} \mathrm{C}$. 
Evaporation was done to make the volume to $10 \mathrm{ml}$. Condensed extracts were preserved in tightly corked labeled bottles and stored in a refrigerator until their use for insect bioassays.

\section{Preparation of stock solution}

Stock solutions of plant extracts were prepared separately by diluting the condensed acetone extracts. Different concentrations of each category of plant extract viz., 10\%, 15\%, $20 \%$ for Necrobia sp. adult and 60\%,80\%,100\% for Dermestes $s p$. larvae were prepared by dissolving the stock solutions in acetone prior to insect bioassay.

\section{De-infestations of dry fish}

Sun dried fish were kept in an oven at $45^{\circ} \mathrm{C}$ for 2-3 hours, packed in polythene bag and sealed to avoid future infestation.

\section{Insect bioassays}

Insect bioassay was conducted in the Microbiology Laboratory of the Department of Fisheries Technology, BAU at $27-30^{\circ} \mathrm{C}$ to determine direct toxicity against Necrobia $\mathrm{sp}$. adult and Dermestes sp. larvae.

\section{Direct toxicity test}

Direct toxicity was determined according to the method of Talukder and Howse (1993). Three different concentrations of each plant extracts (for Necrobia sp. adult 10\%, 15\% and $20 \%$ and for Dermestes $s p$. larvae $60 \%, 80 \%$ and $100 \%$ ) were prepared with respective solvents. Then $5 \mu \mathrm{l}$ of prepared solution was applied to the dorsal surface on the thorax of each insect for Necrobia sp. adult and $30 \mu \mathrm{l}$ for Dermestes sp. larvae by using a micropipette. Ten insects (five males and five females) per replication were treated and each treatment was replicated 3 times. In addition, the same numbers of insects were treated with only basal solvent as control. After treatment, the insects were transferred into $9 \mathrm{~cm}$ diameter petridishes (10 insects/petridish) containing dried fish. Insect mortalities were recorded at 24, 48 and 72 hours after treatment (HAT). Original data were corrected by Abbott's (1987) formula.

$$
\mathrm{P}=\frac{P^{\circ}-C}{100-C} \times 100
$$

Where,

$$
\begin{aligned}
& \mathrm{P}=\text { Percentage of corrected mortality } \\
& \mathrm{P}^{\prime}=\text { Observed mortality }(\%) \\
& \mathrm{C}=\text { Control mortality }(\%)
\end{aligned}
$$

\section{Statistical analysis}

The experimental data were statistically analysed by completely randomized design (factorial CRD) using MSTAT statistical software in a microcomputer. The mean values 
were compared by Duncan's Multiple Range Test (Duncan, 1951). The lethal concentration $50\left(\mathrm{LC}_{50}\right)$ values were calculated by using probit analysis.

\section{RESULTS AND DISCUSSION}

\section{Direct toxic effect}

Application of red chili to Necrobia sp. adult and Dermestes sp. larvae obtained the highest initial mortality due to the presence of piperine (Scngypt and Ray, 1987). Neem also showed satisfactory rapid mortality and proved to be one of the most effective bio-insecticide. Within two days of the application to the insect, red chili produced the highest mortality. Garlic extract did not act as rapidly as red chili and neem, but produced some mortality after two days.

\section{Toxicity on Necrobia sp. adult}

The results of direct toxic effects of different plant extracts against Necrobia sp. adult have been presented in Tables 1-3. The mortality percentage of this insect at 24,48 and 72 hours after treatment (HAT) indicated that red chili extracts possessed the highest mortality. The order of toxicity of the three plant extracts on Necrobia sp. adult were, red chili > neem > garlic. It was found that the mortality was directly proportional to the concentration of plant extract. The interaction effects of dose and time had significant effect on the mortality of Necrobia sp. adult. Their average values were also significant.

Table 1. Direct toxic effect of different plant extracts on Necrobia sp. adult in treated dried fish at different HAT (interaction of plant and time)

\begin{tabular}{l|c|c|c|c}
\hline \multirow{2}{*}{$\begin{array}{c}\text { Name of the } \\
\text { plants }\end{array}$} & \multicolumn{3}{|c|}{ Mortality percentage } & \multirow{2}{*}{ Average } \\
\cline { 2 - 4 } & $24 \mathrm{HAT}$ & $48 \mathrm{HAT}$ & $72 \mathrm{HAT}$ & \\
\hline Neem & 29.167 & 39.167 & 44.167 & $37.500^{\mathrm{b}}$ \\
Red chili & 35.833 & 45.000 & 53.333 & $44.722^{\mathrm{a}}$ \\
Garlic & 19.167 & 25.833 & 38.333 & $27.778^{\mathrm{c}}$ \\
\hline
\end{tabular}

HAT $=$ Hours after treatment

Within column values followed by different superscripts are significantly different $(\mathrm{P}<0.01)$.

\section{Toxicity on Dermestes sp. larvae}

The efficacy of plant extracts was also similar in Dermestes $s p$. larvae as in case of Necrobia $s p$. adult (Table 4-6). The order of toxicity of the three plant extracts on Dermestes sp. larvae were, red chili > neem > garlic. It was also found that the mortality was directly proportional to the concentration of plant extract. 
Table 2. Direct toxic effect of doses of different plant extracts on Necrobia sp. adult in treated dried fish at different HAT (interaction of dose and time)

\begin{tabular}{l|c|c|c|c}
\hline \multirow{2}{*}{ Doses (\%) } & \multicolumn{3}{|c|}{ Mortality percentage } & \multirow{2}{*}{ Average } \\
\cline { 2 - 4 } & $24 \mathrm{HAT}$ & $48 \mathrm{HAT}$ & $72 \mathrm{HAT}$ & \\
\hline Control & $16.67 \mathrm{~g}$ & $16.67 \mathrm{~g}$ & $20.00^{\mathrm{fg}}$ & $17.78^{\mathrm{d}}$ \\
10 & $26.67^{\mathrm{ef}}$ & $36.67^{\mathrm{d}}$ & $45.56^{\mathrm{c}}$ & $36.29 \mathrm{c}$ \\
15 & $33.33^{\mathrm{de}}$ & $44.44^{\mathrm{c}}$ & $53.33^{\mathrm{b}}$ & $43.70^{\mathrm{b}}$ \\
20 & $35.56^{\mathrm{d}}$ & $48.89^{\mathrm{bc}}$ & $62.62^{\mathrm{a}}$ & $48.89^{\mathrm{a}}$ \\
\hline
\end{tabular}

$\mathrm{HAT}=$ Hours after treatment

Within column values followed by different superscripts are significantly different $(\mathrm{P}<0.01)$

Table 3. Direct toxic effect of different plant extracts at different dose level on Necrobia sp. adult in treated dried fish at different HAT (interaction of plant, dose and time)

\begin{tabular}{l|c|c|c|c|c}
\hline \multirow{2}{*}{ Name of the plants } & \multirow{2}{*}{ Doses (\%) } & \multicolumn{3}{|c|}{ Mortality percentage } & \multirow{2}{*}{ Average } \\
\cline { 3 - 5 } & & 24 HAT & 48 HAT & 72 HAT & \\
\hline Control & - & 16.67 & 16.67 & 20.00 & $17.78^{\mathrm{e}}$ \\
\hline Neem & 10 & 26.67 & 36.67 & 43.33 & $35.56^{\mathrm{d}}$ \\
& 15 & 36.67 & 46.67 & 53.33 & $45.56^{\mathrm{c}}$ \\
& 20 & 36.67 & 56.67 & 60.33 & $51.11^{\mathrm{bc}}$ \\
\hline Red chili & 10 & 36.67 & 43.33 & 53.33 & $44.44^{\mathrm{c}}$ \\
& 15 & 43.33 & 56.67 & 63.33 & $54.44^{\mathrm{b}}$ \\
& 20 & 46.67 & 63.33 & 76.67 & $62.22^{\mathrm{a}}$ \\
\hline Garlic & 10 & 16.67 & 30.00 & 40.00 & $28.89^{\mathrm{d}}$ \\
& 15 & 20.00 & 30.00 & 43.33 & $31.11^{\mathrm{d}}$ \\
& 20 & 23.33 & 26.00 & 50.00 & $33.33^{\mathrm{d}}$ \\
\hline
\end{tabular}

HAT $=$ Hours after treatment

Within column values followed by different superscripts are significantly different $(\mathrm{P}<0.01)$

Table 4. Direct toxic effect of different plant extracts on Dermestes sp. larvae in treated dried fish at different HAT (interaction of plant and time)

\begin{tabular}{l|c|c|c|c}
\hline \multirow{2}{*}{ Name of the plants } & \multicolumn{3}{|c|}{ Mortality percentage } & \multirow{2}{*}{ Average } \\
\cline { 2 - 4 } & $24 \mathrm{HAT}$ & $48 \mathrm{HAT}$ & $72 \mathrm{HAT}$ & \\
\hline Neem & 31.67 & 35.83 & 40.00 & $35.83 \mathrm{~b}$ \\
Red chili & 45.00 & 47.50 & 50.83 & $47.78^{\mathrm{a}}$ \\
Garlic & 27.50 & 35.83 & 38.33 & $33.89 \mathrm{~b}$ \\
\hline
\end{tabular}

HAT $=$ Hours after treatment

Within column values followed by different superscripts are significantly different $(\mathrm{P}<0.01)$ 


\section{Probit analysis of direct toxic effect}

The results of the probit analysis for the estimation of $\mathrm{LC}_{50}$ values and their $95 \%$ fiducial limits and the slope of regression lines at 24, 48 and 72 HAT for the mortality of both Necrobia sp. adult are presented in Tables 7-8.

Table 5. Direct toxic effect of doses of different plant extracts on Dermestes $s p$. larvae in treated dried fish at different HAT (interaction of dose and time)

\begin{tabular}{l|c|c|c|c}
\hline \multirow{2}{*}{ Doses (\%) } & \multicolumn{3}{|c|}{ Mortality percentage } & \multirow{2}{*}{ Average } \\
\cline { 2 - 4 } & $24 \mathrm{HAT}$ & $48 \mathrm{HAT}$ & $72 \mathrm{HAT}$ & \\
\hline Control & 10.00 & 10.00 & 10.00 & $10.00 \mathrm{c}$ \\
60 & 37.78 & 45.56 & 48.89 & $44.07 \mathrm{~b}$ \\
80 & 40.00 & 47.78 & 51.11 & $46.29 \mathrm{~b}$ \\
100 & 51.11 & 55.56 & 62.22 & $56.29 \mathrm{a}$ \\
\hline
\end{tabular}

HAT $=$ Hours after treatment

Within column values followed by different superscripts are significantly different $(\mathrm{P}<0.01)$

Table 6. Direct toxic effect of different plant extracts at different dose level on Dermestes $s p$. larvae in treated dried fish at different HAT (interaction of plant, dose and time)

\begin{tabular}{l|c|c|c|c|c}
\hline \multirow{2}{*}{$\begin{array}{c}\text { Name of the } \\
\text { plants }\end{array}$} & Doses (\%) & \multicolumn{3}{|c|}{ Mortality percentage } & \multirow{2}{*}{ Average } \\
\cline { 3 - 5 } & & 24 HAT & 48 HAT & 72 HAT & \\
\hline Control & - & 10.00 & 10.00 & 10.00 & $10.00^{\mathrm{d}}$ \\
\hline Neem & 60 & 33.33 & 36.67 & 40.00 & $36.67 \mathrm{c}$ \\
& 80 & 33.33 & 40.00 & 46.67 & $40.00^{\mathrm{c}}$ \\
& 100 & 50.00 & 56.67 & 63.33 & $56.67^{\mathrm{ab}}$ \\
\hline Red chili & 60 & 50.00 & 56.7 & 60.00 & $55.56^{\mathrm{ab}}$ \\
& 80 & 56.67 & 60.00 & 60.00 & $58.89^{\mathrm{a}}$ \\
& 100 & 63.33 & 63.33 & 73.33 & $66.67 \mathrm{a}$ \\
\hline Garlic & 60 & 30.00 & 43.33 & 46.67 & $40.00^{\mathrm{c}}$ \\
& 80 & 30.00 & 43.33 & 46.67 & $40.00^{\mathrm{c}}$ \\
& 100 & 40.00 & 46.67 & 50.00 & $45.56^{\mathrm{bc}}$ \\
\hline
\end{tabular}

HAT $=$ Hours after treatment

Within column values followed by different superscripts are significantly different $(\mathrm{P}<0.05)$

\section{Direct toxicity on Necrobia sp. adult}

The $\mathrm{LC}_{50}$ values of neem, red chili and garlic at 24 HAT (Table 7) indicated that red chili was the most toxic and garlic was the least toxic plant. Neem showed $0.85 \%$, red chili $0.78 \%$ and garlic $1.68 \%$ toxicity at 24 HAT. They also maintained their toxicity 
accordingly when the $\mathrm{LC}_{50}$ values were compared at $48 \mathrm{HAT}$ (neem $0.73 \%$, red chili $0.29 \%$ and garlic $1.11 \%$ ) and 72 HAT (neem $0.56 \%$, red chili $0.03 \%$ and garlic $0.90 \%$ ).

\section{Direct toxicity on Dermestes sp. larvae}

The $\mathrm{LC}_{50}$ values of three plant extracts were $-0.69 \%, 0.60 \%, 1.15 \%$ toxicity at $24 \mathrm{HAT}$; $0.52 \%, 0.48 \% 0.57 \%$ at $48 \mathrm{HAT}$ and at $72 \mathrm{HAT}$ were $0.44 \%, 0.36 \%, 0.46 \%$ for neem, red chili and garlic respectively which indicated that red chili was the most toxic and garlic was the least toxic among the three plants (Table 8).

Table 7. Relative toxicity (by probit analysis) of different plant extracts treated against Necrobia sp. adult at 24, 48 and 72 HAT

\begin{tabular}{|c|c|c|c|c|c|}
\hline $\begin{array}{c}\text { Name of the } \\
\text { extracts }\end{array}$ & $\begin{array}{l}\text { No. of the } \\
\text { insect used }\end{array}$ & $\mathrm{LC}_{50}$ values & $\begin{array}{c}95 \% \text { fiducial } \\
\text { limit }\end{array}$ & $\begin{array}{c}\chi^{2} \\
\text { values }\end{array}$ & Slope \pm DE \\
\hline \multicolumn{6}{|l|}{24 HAT } \\
\hline Neem & 10 & 0.85 & $-5.07-4.93$ & 0.003 & $2.28 \pm 0.81$ \\
\hline Red chili & 10 & 0.78 & $-5.12-4.90$ & 0.111 & $2.60 \pm 0.81$ \\
\hline Garlic & 10 & 1.682 & $-4.92-5.37$ & 0.060 & $1.30 \pm 0.83$ \\
\hline \multicolumn{6}{|l|}{48 HAT } \\
\hline Neem & 10 & 0.73 & $-5.11-4.84$ & 0.0008 & $1.90 \pm 0.80$ \\
\hline Red chili & 10 & 0.29 & $-5.58-4.51$ & 0.0007 & $0.79 \pm 0.80$ \\
\hline Garlic & 10 & 1.11 & $-5.02-5.11$ & 0.235 & $1.88 \pm 0.82$ \\
\hline \multicolumn{6}{|l|}{72 HAT } \\
\hline Neem & 10 & 0.56 & $-5.19-4.69$ & 0.005 & $0.38 \pm 0.79$ \\
\hline Red chili & 10 & 0.03 & $-6.67-3.78$ & 0.011 & $0.41 \pm 0.84$ \\
\hline Garlic & 10 & 0.90 & $-5.06-4.97$ & 0.164 & $2.22 \pm 0.81$ \\
\hline
\end{tabular}

HAT $=$ Hours after treatment

Values were based on one solvent, three concentrations and three replications of 10 insects each $X^{2}=$ Goodness of fit

\section{Probit regression lines}

The probit regression lines for the effect of three different plant extracts are shown in Figs. 1-3. The insect mortality rate showed positive correlation with the doses in all cases. The probit regression lines for the effects of three different plant extracts on Necrobia sp. adult and Dermestes sp. larvae showed a clear linear relationship between probit-mortality and the doses used for them.

The calculated probit regression equation of neem extracts for Necrobia sp. adult (Fig. 1) at 24 HAT was, $Y=2.0111 x+1.2546$, at 48 HAT was $Y=2.3314 x+2.0562$, and for 72 HAT was $Y=2.8836 x+2.1309$. It was indicated from above equations that mortality rate increased with the increase of concentration and time.

The calculated probit regression equation of red chili extracts for Necrobia sp. adult (Fig. 2) at 24 HAT was, $Y=2.4726 x+1.6355$, at 48 HAT was $Y=2.9682 x+2.2452$, and for 72 HAT 
was $Y=3.3168 x+2.7793$. The equations indicate that mortality rate increases with increase of concentration and time.

Table 8. Relative toxicity (by probit analysis) of different plant extracts treated against Dermestes sp. larvae at 24, 48 and 72 HAT

\begin{tabular}{|c|c|c|c|c|c|}
\hline $\begin{array}{l}\text { Name of the } \\
\text { extracts }\end{array}$ & $\begin{array}{l}\text { No. of the } \\
\text { insect used }\end{array}$ & $\mathrm{LC}_{50}$ values & $\begin{array}{c}95 \% \text { fiducial } \\
\text { limit }\end{array}$ & $\begin{array}{c}\chi^{2} \\
\text { values }\end{array}$ & Slope \pm DE \\
\hline \multicolumn{6}{|l|}{24 HAT } \\
\hline Neem & 10 & 0.69 & $-5.16-4.85$ & 0.010 & $2.31 \pm 0.81$ \\
\hline Red chili & 10 & 0.60 & $-5.20-4.77$ & 0.002 & $1.52 \pm 0.80$ \\
\hline Garlic & 10 & 1.15 & $-4.93-5.06$ & 0.002 & $1.16 \pm 0.81$ \\
\hline \multicolumn{6}{|l|}{48 НАТ } \\
\hline Neem & 10 & 0.52 & $-6.27-5.71$ & 0.208 & $4.98 \pm 0.96$ \\
\hline Red chili & 10 & 0.48 & $-7.02-6.39$ & 0.419 & $5.48 \pm 1.08$ \\
\hline Garlic & 10 & 0.57 & $-5.38-4.90$ & 0.045 & $2.84 \pm 0.38$ \\
\hline \multicolumn{6}{|l|}{72 HAT } \\
\hline Neem & 10 & 0.44 & $-5.43-4.73$ & 0.174 & $1.54 \pm 0.82$ \\
\hline Red chili & 10 & 0.36 & $-5.44-4.56$ & 0.0005 & $0.76 \pm 0.81$ \\
\hline Garlic & 10 & 0.46 & $-7.81-7.15$ & 0.062 & $5.88 \pm 1.21$ \\
\hline
\end{tabular}

HAT $=$ Hours after treatment

Values were based on one solvent, three concentrations and three replications of 10 insects each $X^{2}=$ Goodness of fit

The calculated probit regression equation of garlic extracts for Necrobia sp. adult (Fig. 3) at 24 HAT was, $Y=2.1379 x-0.0027$, at 48 HAT was $Y=2.8152 x+0.1879$, and for 72 HAT was $Y=4.644 x+0.691$. It was again indicated from the above equations that mortality rate increased with increase of concentration and time. All three cases the highest mortality was at 72 HAT.

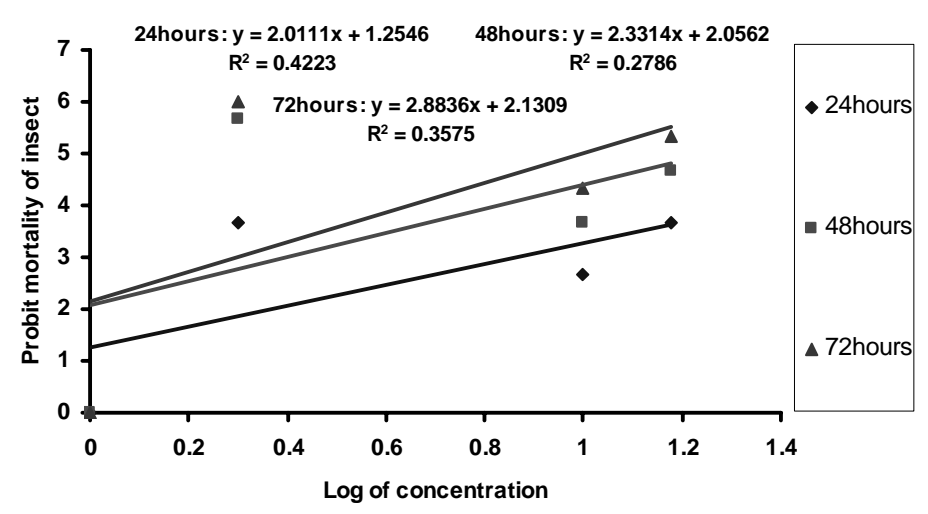

Fig. 1. Relationship between probit mortality and log doses of neem extracts on Necrobia sp. adult at 24, 48 and 72 hours after treatment 
The probit regression lines for the effects of three plant extracts on Dermestes $s p$. larvae also showed similar distinct linear relationship between probit mortality and the doses used (Figs. 4, 5 and 6). Highest mortality was also found at 72 HAT in all three extracts.

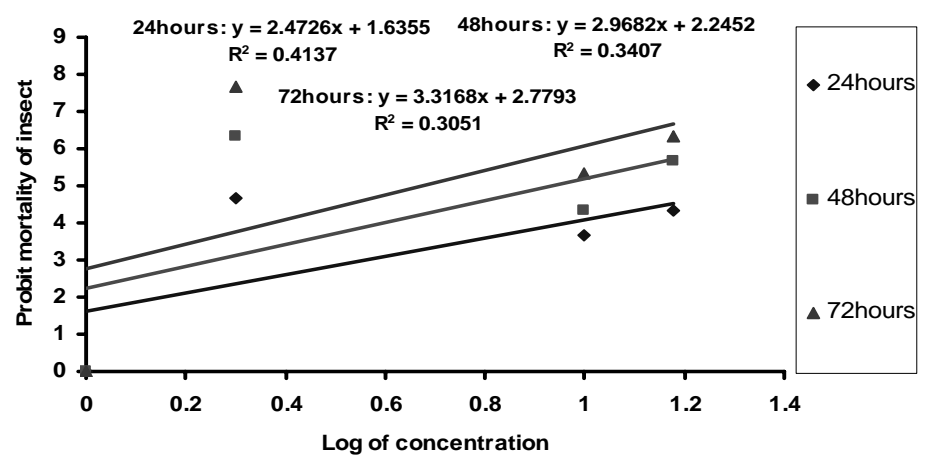

Fig. 2. Relationship between probit mortality and log doses of red chili extracts on Necrobia sp. adult at 24,48 and 72 hours after treatment

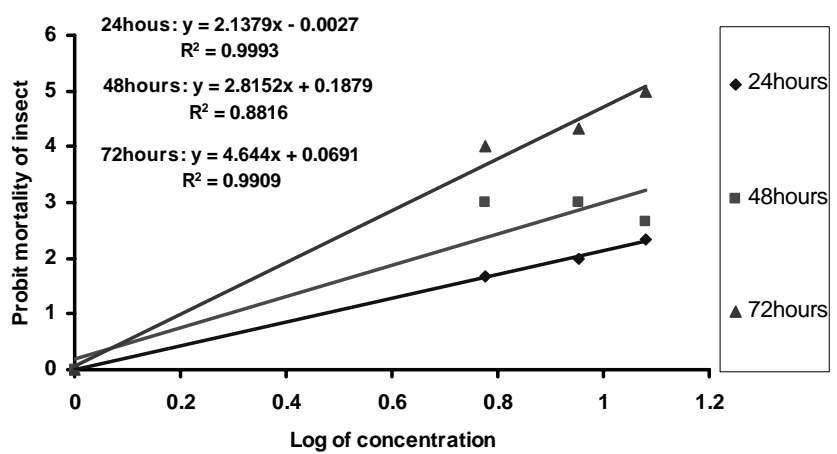

Fig. 3. Relationship between probit mortality and log doses of garlic extracts on Necrobia sp. adult at 24,48 and 72 hours after treatment

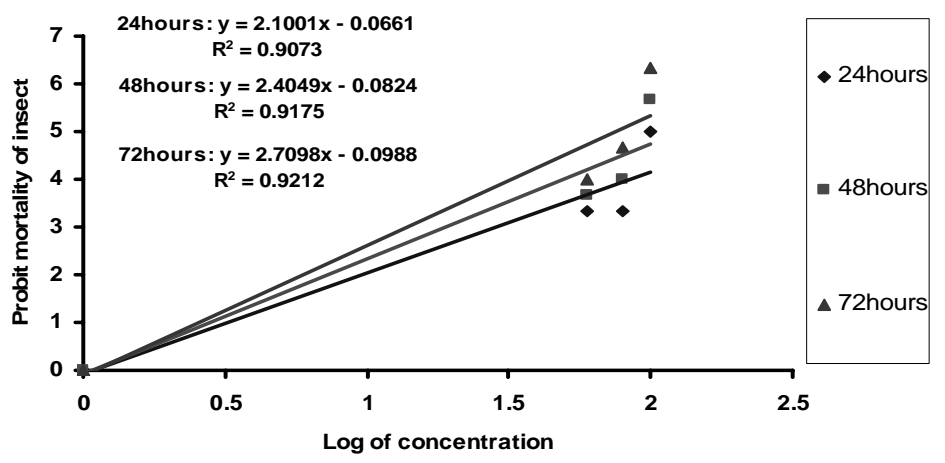

Fig. 4. Relationship between probit mortality and log doses of neem extracts on Dermestes sp. larvae at 24,48 and 72 hours after treatment 


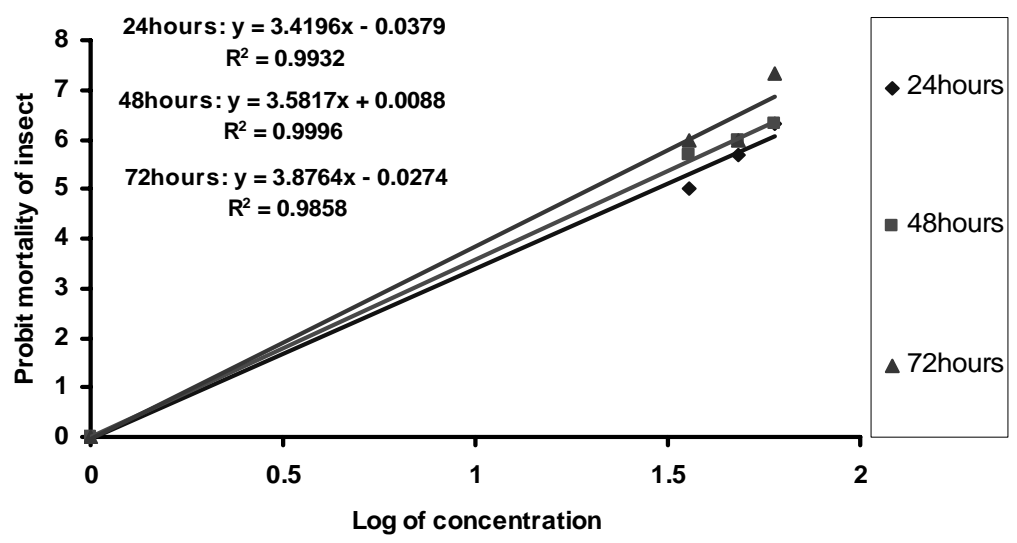

Fig. 5. Relationship between probit mortality and log doses of red chili extracts on Dermestes sp. larvae at 24, 48 and 72 hours after treatment

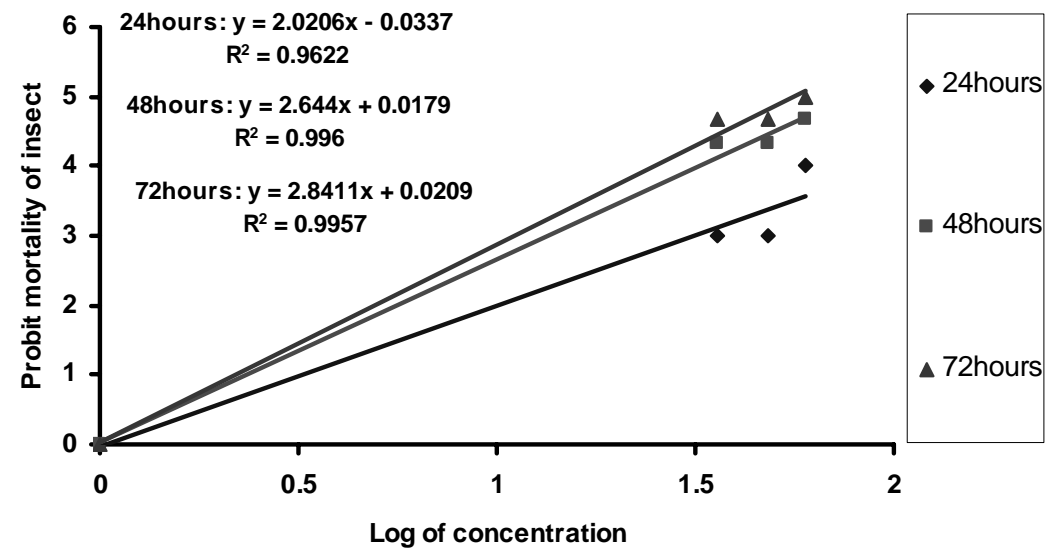

Fig. 6. Relationship between probit mortality and log doses of garlic extracts on Dermestes sp. larvae at 24, 48 and 72 hours after treatment

\section{CONCLUSION}

For Necrobia sp. adult $\mathrm{LC}_{50}$ values of red chili $(0.78 \%)$, neem $(0.85 \%)$ and garlic $(1.68 \%)$ at 24 HAT indicated that red chili had the highest toxic effect among these three herbs. Red chili possessed the highest toxic effect at 48 HAT $(0.29 \%)$ and 72 HAT $(0.03 \%)$. For larvae of Dermestes sp. the $\mathrm{LC}_{50}$ values of red chili was $0.60 \%$, of neem was $0.69 \%$ and of garlic was $1.15 \%$ at $24 \mathrm{HAT}$, again indicating the red chili as the most toxic plant. All the three plant extracts had repellent and toxic effects on dried fish beetle and mite. Red chili extract was found to be the most toxic, while neem to be the most repellent. 


\section{REFERENCES}

Abbott, W. S. 1987. A method of computing the effectiveness of an insecticide. J. American Mosquito Cont. Assoc., 3: 302-303.

Duncan, D. B. 1951. A significance test for differences between ranked treatments in an analysis of variance. Virginia J. Sci., 2 (9): 171-189.

FAO, 1981. The prevention of losses in cured fish. FAO Fisheries Technical Paper No. 219. 87 pp.

Golob P. and Webley D. J. 1980. The use of plants and minerals as traditional Protestants of stored products. Tropical Products Institute G 138.

Metcalf, R. L. and W. H. Luckmann. 1975. Introduction to insect pest management. pp. 235-273. Jhon Willey and Sons, New York. 587 p.

Meynell P. J. (1978). Reducing blowfly spoilage of sun drying fish in Malawi using Pyrethrum. Indo-Pacific Fishery Commission Symposium on Fish Utilization Technology and Marketing in the IPFC Region, Manila, Philippines. FAO IPEC/78/SYMP/37.

Nowsad, A. K. M. A. 2005. Low-cost Fish Processing in Coastal Bangladesh BGD/97/017, Field Dec: 5/2005. FAO. 88pp.

Pimental, D. 1981. An overview of integrated pest management (Mimeograph). Department of Entomology, Section of Ecology and Systematic, Cornell University, Ithaca, NY. p. 52.

Poulter, R. G., Ames G. R. and Evans N. J. (1988) Post-harvest losses in traditionally processed fish products in less developed countries. In: Post-harvest Fishery Losses. Proceeding of an International Workshop Held at the University of Rhode Island, 12-16 April 1987, pp. 133-146.

Scngypt, C. E. and D. L. Ray. 1987, Derivations of piperic acid and their toxicity towards houseflies, Contribuce Boyce, Thompson Inst., 16: 433-442.

Sighamony, S., Anees, I., Chandrakala, T. S. and Osmani, Z. 1986. Efficacy of certain indigenous plant product as grain protectants against Sitophilus oryzae L. and Rhizopertha dominica (F). J. Stored Product Res., 22(1): 21-23.

Talukder, F. A. and P. F. Howse. 1993. Deterrents and insecticidal effect of extracts of pithraj, Aphanamixis polystachya (Meliaceae) Against Tribolium castaneum in storage. J. Pest Manag., 40(1): 94-97.

Talukder, F. A. and Howse, P. F. 1995. Evaluation of Aphanamixis polystachya as Bangladesh source of repellent. Antifeedant, toxicant and protectant in storage against Tribolium Castaneum Herbst. J. Stored Prod. Res., 31(1): 55-61.

Xie, Y. S., P. G. Fields and M. B. Isman. 1995. Repellency and toxicity of azadirachtin and neem concentrates to three stored product beetles. J. Econ. Entomol., 88: 1024-1031. 